Vol. LXV 2014

\title{
THE RESULTS ON METAL SURFACE MICRO GEOMETRY MODIFICATION BY APPLYING ELECTRIC DISCHARGES IN IMPULSE
}

\author{
Dorin GUZGAN \\ “Alecu Russo Balti” State University, Republic of Moldova, Department of Real, Economic and Media Science, \\ 38 Puskin str., Balti, Republic of Moldova, 3100
}

\begin{abstract}
The experimental results aimed at modification of metal surface micro geometry by applying electric discharges in impulse are presented in this paper. Taylor cone-shaped asperities were extracted from the metal piece on the flat and cylindrical surface. SEM and EDX analysis of the processed surfaces were investigated.
\end{abstract}

Key words: discharge, geometry, cone, Taylor, plasma.

\section{Introduction}

The modification of surface micro geometry is one of the most current problems of modern technologies (Topală, 2007; Gabovich, 1983; Luban, 1990). The surface that can be described using mathematical relationships in most cases is a linear one which due to its features aims at an ideal surface. For real surfaces, their nature determines not only the active area but often lends it new properties of exploitation. The area of the real surface contributes to changing the character of interaction with the environment and other active surfaces of the parts with which the piece makes couples (for parts used in machine building). For radiating surfaces (of heat, waves, electric and magnetic fields) or for those that absorb different types of radiation (thermal radiation receivers, light waves, electromagnetic radiation, etc.) both geometry and the active surface area play a decisive role concerning their features mentioned above. The following are the results of experimental research on the extraction from the metal piece surface of Taylor cone-shaped asperities of different dimensions and with a prescribed distribution on the metal piece surfaces via the method of electric discharges in impulse (EDI).

\section{Methodology of experimental research}

Experimental investigations have been performed under normal conditions, in the air, at room temperature for solitary discharges. To perform the experimental research we used a current pulse generator (Topală, 2008).

In the process of research, the size of the interstice between electrodes was measured withal dial comparator whose accuracy was $0.01 \mathrm{~mm}$ and it was permanently controlled by MPB-2 microscope. The dimensions of (Taylor cone) asperities were measured with an MBS-9 microscope and the scanning electronic microscope QUANTA 200. Electrodynamics parameters (pulse duration, pulse current variation, voltage drop on the interstice, and the energy released by a solitary discharge) are determined by oscilocopying (Topală, 2008; Gabovich, 1983).

To carry out the investigation cylindrical or flat samples were made from different materials whose properties are shown in Table 1.

Table 1: Physical-mechanic properties of materials used in the process of experimental investigations

\begin{tabular}{|l|c|c|c|c|}
\hline \multicolumn{1}{|c|}{ Material } & $\begin{array}{c}\text { Melting } \\
\text { temperature }\left({ }^{\mathbf{o}} \mathbf{C}\right)\end{array}$ & $\begin{array}{c}\text { Hardness } \\
\mathbf{( H B )}\end{array}$ & $\begin{array}{c}\text { Density } \\
\left(\mathbf{k g}^{\mathbf{2}} \mathbf{m}^{\mathbf{3}} \mathbf{1 0}^{-\mathbf{3}} \mathbf{)}\right.\end{array}$ & $\begin{array}{c}\text { Specific thermal capacity } \\
(\mathbf{c a l} / \mathbf{( g ~ d e g r e e}) \mathbf{)}\end{array}$ \\
\hline Steel 45 & $1300-1400$ & $179-207$ & $7,7-7,9$ & 0,11 \\
\hline $\mathrm{W}+10 \% \mathrm{Re}$ & 3180 & 200 & 21,02 & 0,0326 \\
\hline $\mathrm{NiCr}$ & $1100-1400$ & $140-150$ & $8,2-8,5$ & 0,44 \\
\hline
\end{tabular}


To perform the experimental research on extracting Taylor cones on the cylindrical surface via EDI, a pair of electrodes was used: a horseshoe-shaped wire piece made of the materials presented above and the tool - electrode that is made of the same material and has the form of a cylindrical bar or a bar with a peak sharpened at an angle of $20^{\circ}-30^{\circ}$.

The electrodes previously processed according to the method described above were bound in the bumpers of the fixing device. Then the electrodes were manually brought closer to each other to get in contact with one another and the interstice size was selected (by moving them in the opposite direction with a screw mechanism - a screw nut of $1 \mu \mathrm{m})$.

Figure 1 shows the schemes of positioning the electrodes used in experimental research and their connection in the discharge circuit of the current pulse generator.

Figure 1: Schemes of positioning the electrodes used in the process of experimental research and their connection in the discharge circuit of the current pulse generator: the piece is positioned in the upper side.

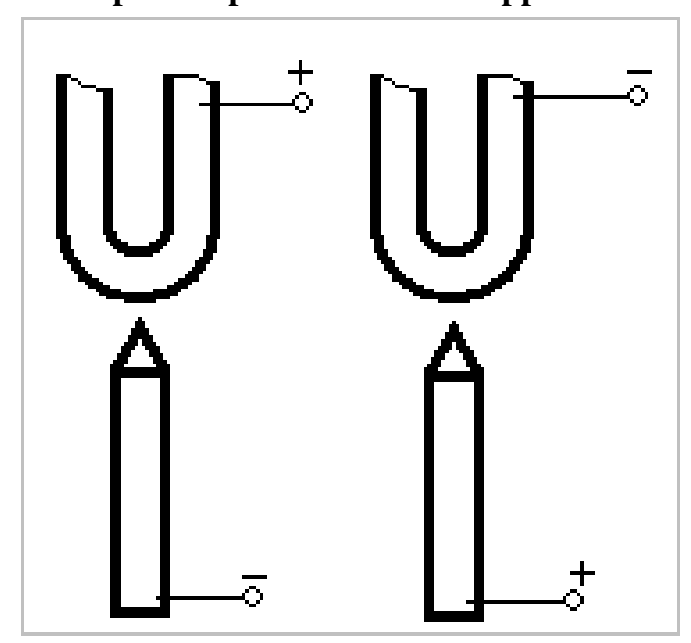

For the experimental research on extracting Taylor cone asperities on a flat surface via EDI we used the pair of electrodes: the piece-plaque made of steel 45 with a flat working surface up to 20x20 mm and the tool electrode made of stainless steel sharpened at the angle of $20^{\circ}$ (Fig. 2).

In order to determine the extraction optimum conditions of Taylor cone shaped asperities we performed the microscopic analysis of the processed surface by measuring the diameter of the cone basis extracted depending on the power regime of the pulse generator (charging voltage of the condenser battery).

Figure 2: The scheme of positioning the piece to be processed with a flat surface and the tool electrode in the process of experimental research and their connection in the discharge circuit of the current pulse generator.

The piece to be processed

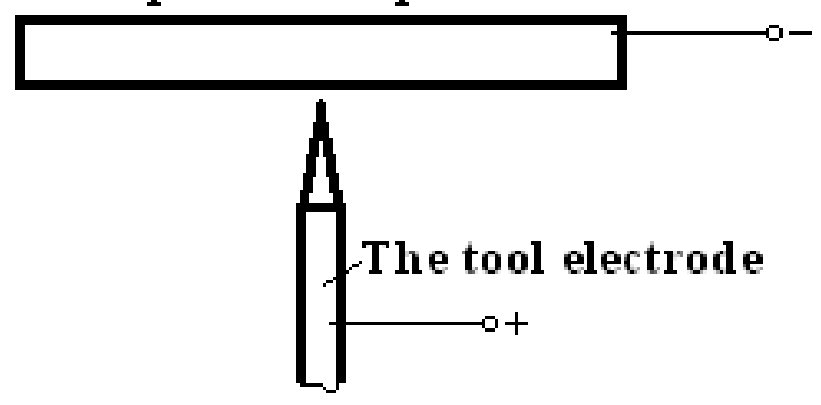

The condenser battery capacity changes step by step (at the step of $100 \mu \mathrm{F}$ ) within the limits of $100-600 \mu \mathrm{F}$ for certain values of the condenser battery voltage. For certain cases these voltage values constituted 60V, 80V, 100V, 120 and 140V.

To determine the influence of pulse duration on the Taylor cone geometry in the process of EDI, 
the energy accumulated on the condenser battery changes keeping the pulse duration constant. Researches were made for more values of the discharge pulse duration, namely $100 \mu \mathrm{s}, 125 \mu \mathrm{s} 160 \mu \mathrm{s}, 180 \mu \mathrm{s}, 200 \mu \mathrm{s}$ and $220 \mu$ s The research was repeated several times in order to obtain accurate results.

Wolfram wire + RE10\% with the diameter $\mathrm{d}=0,2 \mathrm{~mm}$ was used as electrodes.

\section{Results and interpretations}

In the previous works carried out by the author of this paper it was determined that the appearance of the liquid phase on the machined surface, the asperity extraction and its freezing (ultrafast solidification of the material in the form of asperity) are necessary to get surfaces with Taylor cone shaped asperities. Experiments show that to achieve the technology of surface micro geometry change by extracting Taylor cone shaped asperities it is necessary to meet the following conditions:

- $\quad$ ensuring the local (Topală, 1990; Topală 2007; Topală, 2008) melting of the piece determined by the relationship (1):

$$
Q=\frac{4 W}{\pi d_{C}^{2} S} \geq Q_{t o p}
$$

where Q - is the amount of heat released into the plasma channel during EDI, W - is the energy emitted in the plasma channel, $d_{C}$ - is the diameter of the liquid phase crater on the cathode surface, $S$ - is the size of the gap between electrodes, $Q_{\text {top }}$ - is the volumetric density of the piece material melting determined by the relation $\mathrm{Q}_{\text {top }}=\mathrm{q}_{\mathrm{top}} \cdot \rho ; \mathrm{q}_{\mathrm{top}}, \rho$ are respectively the specific heat of melting and the density of the piece material;

- $\quad$ An electric field having the power of about $10^{8} \mathrm{~V} / \mathrm{m}$ gap will be created in the interstice (Luban, 1990):

$$
E_{c r}=\sqrt[4]{64 \pi^{2} \rho g \gamma \cdot 3 \cdot 10^{4}}
$$

where $E_{c r}$ - is the critical electric field strength; $\rho$ - is the metal density, $g$ - is the free fall acceleration; $\gamma$ is the surface voltage of the liquid material;

$$
\sigma_{c r}=\sqrt{\frac{g \rho \gamma}{4 \pi^{2}}}
$$

where $\sigma_{\mathrm{cr}}$ - is the critical density of electric charge on the liquid metal surface;

$$
j=\frac{4 I_{\max }}{\pi d_{c r}^{2}}
$$

$\mathrm{j}$ - is the current density in the gap throughout a discharge (Topală, 2007); $I_{\max }$ - is the current amplitude value in impulse; $d_{\mathrm{cr}}$ - is the erosion crater diameter on the work piece surface (Topală, 2008).

The direction of the action of the electric field will coincide with the direction of the weight force action. Figure 3 shows images of samples with semicircular active surfaces from which conical menisci were extracted as a result of electric discharges in impulse in different processing power regimes.

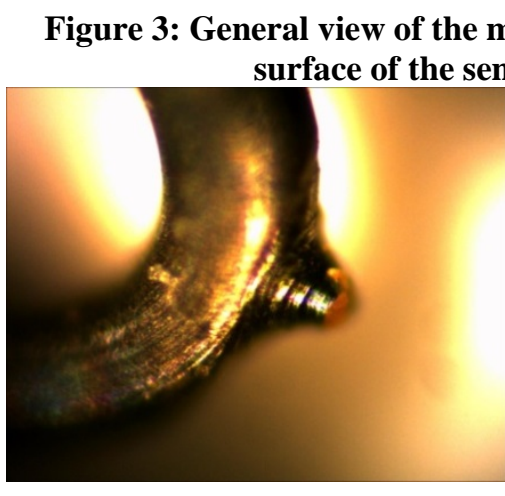

a)

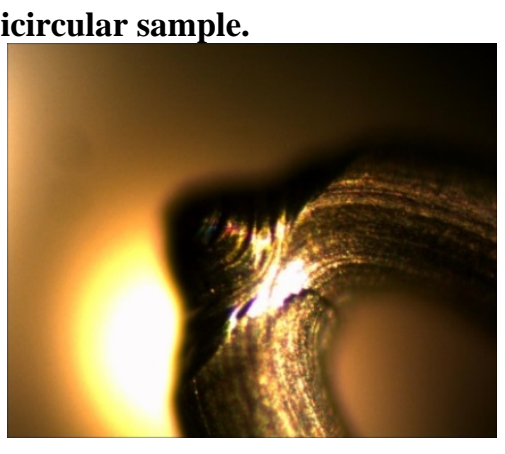

b)

The sample material and the tool electrode $\mathrm{W}+\mathrm{Re} 10 \%$; $\mathrm{U}=80 \mathrm{~V}, \mathrm{C}=600 \mu \mathrm{F}, \mathrm{L}=0.3 \mathrm{~mm}, \mathrm{n}=1$, $\varnothing_{\text {electrode tool }}=\varnothing_{\text {sample }}=0,2 \mathrm{~mm}$ :

a) the piece was placed at the top as anode; b) the piece was placed at the bottom as anode

We can see in Figure 3a that the form of the extracted meniscus is more elongated than that of the meniscus in Figure 3b due to the work of the component of gravitational attraction force (that is why the meniscus in Figure 3 is more elongated; in this case, the weight force coincides with the direction of the 
meniscus extraction. In figure 3b, we obtain a flatter cone because the weight force is directed against the direction of conic asperity growth).

The surface micro geometry modification increase its area by several times, Taylor cones serve as concentrators of electric charge. This can be used in manufacturing of thermo-cathodes with high emission performances. In the work (Topală 2012; Topală 2013) it was shown that the electronic thermoemission of processed cathodes increases by 10 times.

The craters formed on the flat surface with the conical meniscuses have changed the micro geometry of the cathode active surface as Fig. 3, 4, 5 and 6 are shown.

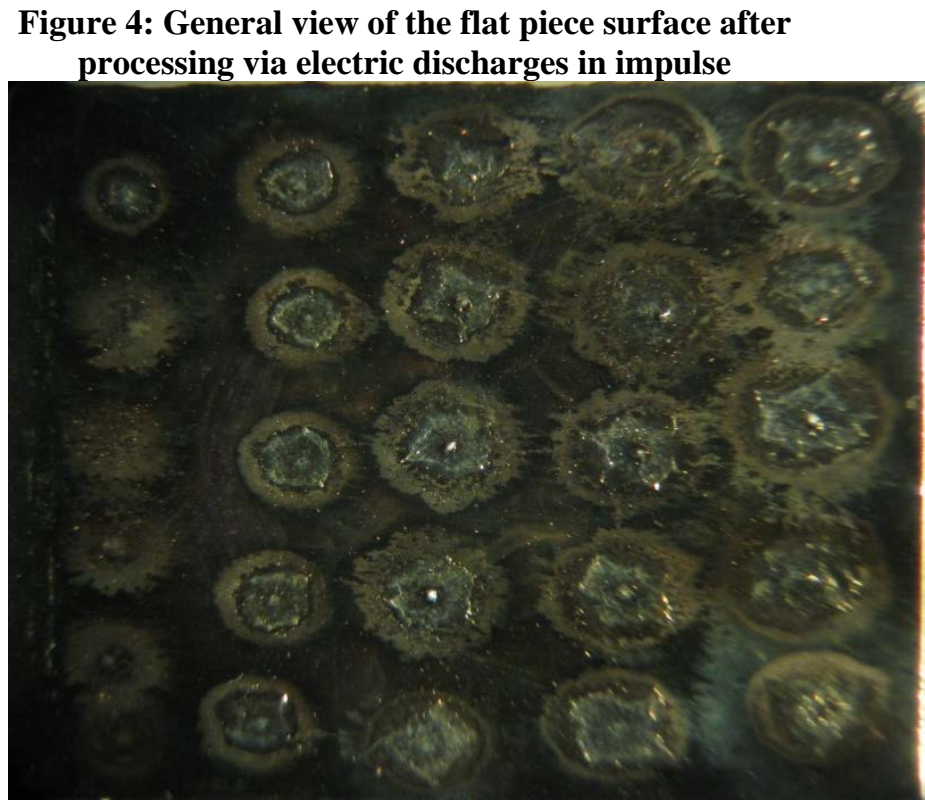

The application of the modern research apparatus (SEM) allowed to state the fact that the lateral surface of the formed asperities is a complicated one and presents micro and nanometric undulations (fig. $5 a)$. These undulations may be caused by the variation of the current in electric discharge. It has already been shown that EDI is multichannel (Topală, 2008). Some discharge channels die, others are appear, due to which the current of solitary electric discharge has a pulse character. The side surface undulations also increase the active surface area and undoubtedly the capacity of its thermo-electronic emission.

If we take into account the fact that the electric discharge is multichannel, electrode spots appear and die and the pulsed electric current has a variable nature in time with nanosecond discontinuities, it leads to the appearance of transversal capillary waves (Luban, 1990; Stavitskii, 2001; Grigoriev, 2004). The wavelength of these capillary waves as we can see in Fig. 5, b constitutes:

$$
\lambda_{\text {med }} \approx 3 \mu \mathrm{m}
$$

Figure 5: Morphology of Taylor cone shaped asperity surface

a) Image obtained via SEM method; b) Determination of average wave length for the transversal wave

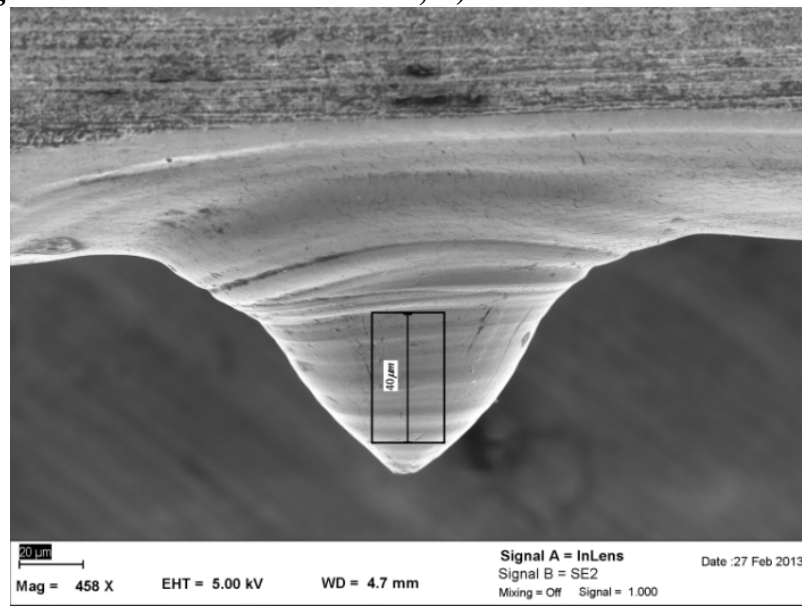

a)

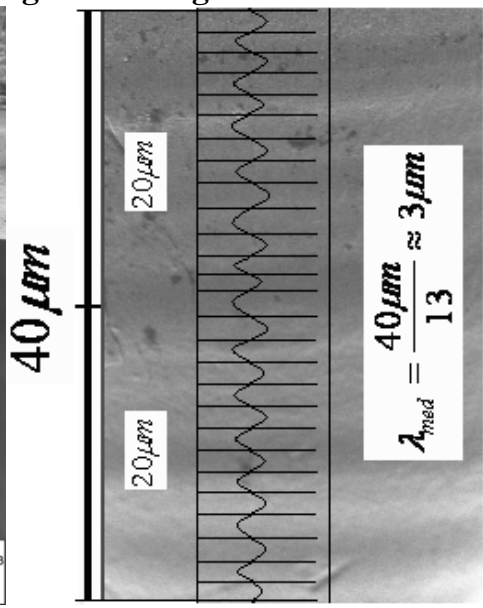

b) 
Depending on the working environment in the interstice in the asperity surface we can synthesize phases containing oxygen, nitrogen, hydrogen and carbon, which in their turn modify the functional properties of cathodes applied at electronic thermal emission (Fig. 6, 7 and 8).

Figure 6: EDX analysis on the cathode surface in four different points

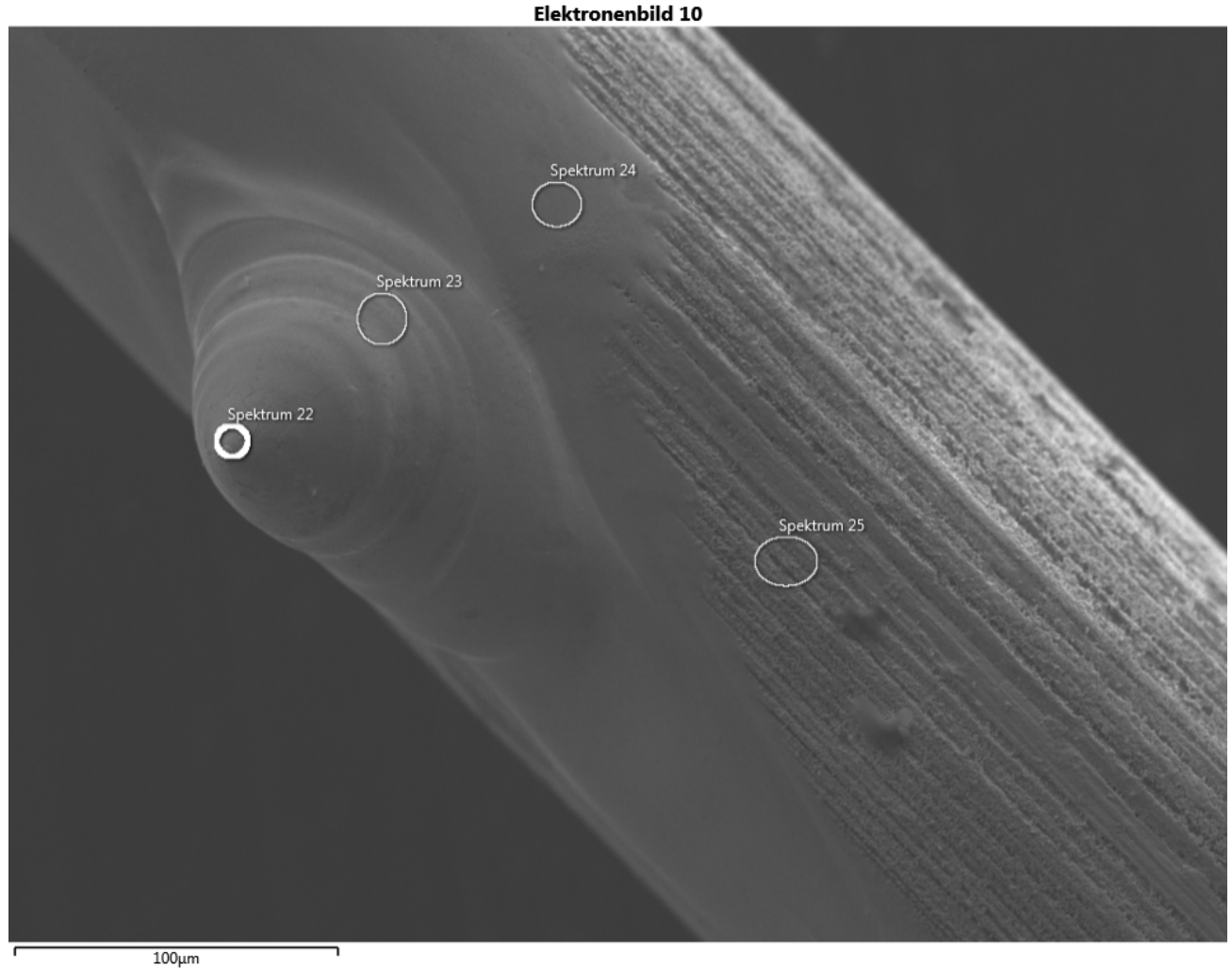

The graphic and tabular results given below allow us to talk about the chemical content of the cathode material at various points including the material the conic meniscus is made of.

Figure 7: EDX analysis of a meniscus extracted from the Wolfram cathode:

a) at the top of the meniscus; b) at the basis of the meniscus

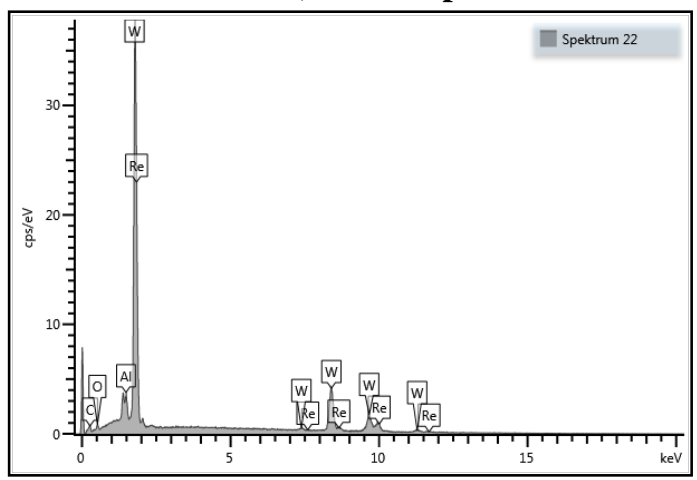

a)

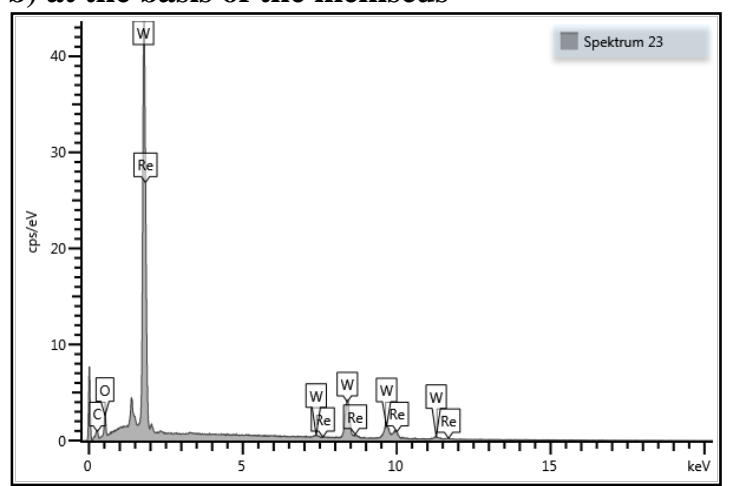

b)

Table 2: The chemical content in the centre of the conic meniscus (Fig. 7 a):

\begin{tabular}{|l|r|r|r|r|r|}
\hline Elements & $\begin{array}{c}\text { Apparent } \\
\text { concentration }\end{array}$ & $\begin{array}{c}\text { Apparent } \\
\text { concentration }\end{array}$ & $\begin{array}{c}\text { \% By } \\
\text { mass }\end{array}$ & $\begin{array}{c}\text { Mass\% } \\
\text { Sigma }\end{array}$ & $\begin{array}{c}\text { The default } \\
\text { name }\end{array}$ \\
\hline $\mathrm{O}$ & 6.95 & 0.02337 & 2.75 & 0.29 & $\mathrm{SiO} 2$ \\
\hline $\mathrm{Al}$ & 7.40 & 0.05315 & 1.57 & 0.08 & $\mathrm{Al} 2 \mathrm{O} 3$ \\
\hline $\mathrm{W}$ & 326.58 & 3.26581 & 86.98 & 0.60 & $\mathrm{~W}$ \\
\hline $\mathrm{Re}$ & 28.47 & 0.28469 & 8.70 & 0.56 & $\mathrm{Re}$ \\
\hline Total: & & & 100.00 & & \\
\hline
\end{tabular}


Table 3: The chemical content at the basis of the conic meniscus (Fig. 7 b):

\begin{tabular}{|l|r|r|r|r|r|}
\hline Elements & \multicolumn{1}{|c|}{$\begin{array}{c}\text { Apparent } \\
\text { concentration }\end{array}$} & $\begin{array}{c}\text { Apparent } \\
\text { concentration }\end{array}$ & $\begin{array}{c}\text { \% By } \\
\text { mass }\end{array}$ & \multicolumn{1}{c|}{$\begin{array}{c}\text { Mass\% } \\
\text { Sigma }\end{array}$} & $\begin{array}{c}\text { The default } \\
\text { name }\end{array}$ \\
\hline $\mathrm{O}$ & 31.00 & 0.10432 & 9.55 & 0.34 & $\mathrm{SiO} 2$ \\
\hline $\mathrm{W}$ & 376.42 & 3.76423 & 82.66 & 0.57 & $\mathrm{~W}$ \\
\hline $\mathrm{Re}$ & 31.11 & 0.31113 & 7.79 & 0.53 & $\mathrm{Re}$ \\
\hline Total: & & & 100.00 & & \\
\hline
\end{tabular}

Figure 8: EDX analysis on the surface of the Wolfram cathode:

a) close to the crater; b) one arbitrary point on the cathode surface

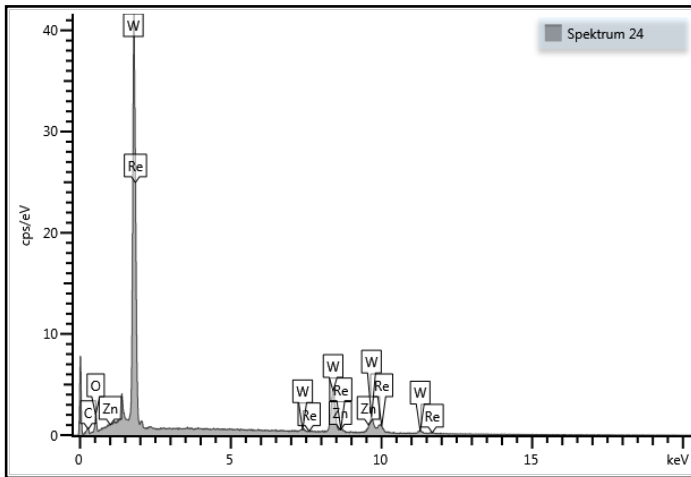

a)

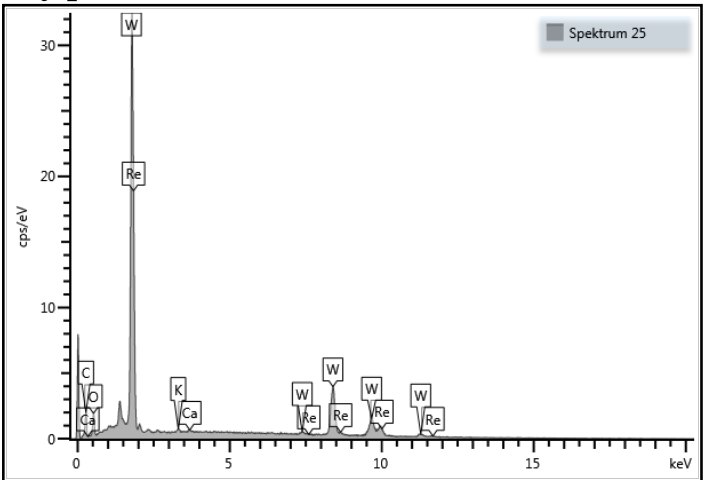

b)

Table 4: The chemical content of the Wolfram cathode close to the crater (Fig. 8 a):

\begin{tabular}{|l|r|r|r|r|r|}
\hline Elements & $\begin{array}{c}\text { Apparent } \\
\text { concentration }\end{array}$ & $\begin{array}{c}\text { Apparent } \\
\text { concentration }\end{array}$ & $\begin{array}{c}\text { \% By } \\
\text { mass }\end{array}$ & \multicolumn{1}{c|}{$\begin{array}{c}\text { Mass\% } \\
\text { Sigma }\end{array}$} & \multicolumn{2}{|c|}{$\begin{array}{c}\text { The default } \\
\text { name }\end{array}$} \\
\hline $\mathrm{O}$ & 23.99 & 0.08074 & 8.14 & 0.33 & $\mathrm{SiO} 2$ \\
\hline $\mathrm{Zn}$ & 0.53 & 0.00534 & 0.11 & 0.68 & $\mathrm{Zn}$ \\
\hline $\mathrm{W}$ & 353.12 & 3.53118 & 84.09 & 0.81 & $\mathrm{Re}$ \\
\hline $\mathrm{Re}$ & 28.15 & 0.28154 & 7.66 & 0.54 & \\
\hline Total: & & & 100.00 & & \\
\hline
\end{tabular}

Table 5: The chemical content of the cathode made of Wolfram (Fig. 8 b):

\begin{tabular}{|l|r|r|r|r|r|}
\hline Elements & \multicolumn{1}{|c|}{$\begin{array}{c}\text { Apparent } \\
\text { concentration }\end{array}$} & $\begin{array}{c}\text { Apparent } \\
\text { concentration }\end{array}$ & $\begin{array}{c}\text { \% By } \\
\text { mass }\end{array}$ & \multicolumn{1}{c|}{$\begin{array}{c}\text { Mass\% } \\
\text { Sigma }\end{array}$} & \multicolumn{1}{c|}{$\begin{array}{c}\text { The default } \\
\text { name }\end{array}$} \\
\hline $\mathrm{O}$ & 24.81 & 0.08348 & 10.45 & 0.34 & $\mathrm{SiO} 2$ \\
\hline $\mathrm{K}$ & 1.50 & 0.01270 & 0.51 & 0.08 & $\mathrm{KBr}$ \\
\hline $\mathrm{Ca}$ & 0.90 & 0.00802 & 0.28 & 0.08 & Wollastonite \\
\hline $\mathrm{W}$ & 281.20 & 2.81197 & 84.63 & 0.58 & $\mathrm{~W}$ \\
\hline $\mathrm{Re}$ & 12.01 & 0.12011 & 4.13 & 0.54 & $\mathrm{Re}$ \\
\hline Gesamt: & & & 100.00 & & \\
\hline
\end{tabular}

Using the data presented in Tables 2-5 and Fig. 7 a, b -8 a, b we may state that the largest amount of oxygen dissolves in the piece material at the basis of the meniscus and at the edge of the crater, the place where the favorable conditions for this are met (the action of the plasma throughout the period of the impulse, the temperature at the periphery of the plasma channel is lower, the diffusion processes take place in the liquid state of the piece material), while at the top of the conic asperity the amount of dissolved oxygen is lower (processes of intensive evaporation take place here while the freezing of the melted metal takes place at speeds of $10^{6} \mathrm{~K} / \mathrm{s}$ ).

\section{Conclusions:}

- surface micro geometry modification increase its area by several times, Taylor cones serve as concentrators of electric charge, it can be used in manufacturing of thermo-cathodes with high emission performances;

- the amount of oxygen dissolved in the surface layer of the metal pieces under the action of the plasma channel of electric discharges in impulse depends on the chemical content of the piece alloy and on the processing power regime, the oxygen presence will be studied in the future investigations;

- the wavelength of formed Taylor cones by applying EDI constitutes $\approx 3 \mu \mathrm{m}$;

- the process of Taylor cones formation by applying EDI is stronger when the work piece is 
connected in the discharge circuit as anode.

\section{References}

- Gabovich, M. D. (1983). Liquid metallic ion emitters. Advances of Physical Sciences. Vol. 140. Issue 1, pp. 137-151.

- $\quad$ Gabovich, M. D.; Praznyi, V. Ya. (1983). On the mechanism of excitation of nonlinear capillary waves on the surface of the liquid metal in contact with the ion plasma. Journal of Experimental and Theoretical Physics. Vol. 85, issue 1, pp. 146.

- $\quad$ Grigoriev, A. I.; Shiryaeva, S. O.; Belonozhko, D. F.; Klimov, A. V. (2004). About Taylor cone shape and characteristic time of its growth. Electronic processing of materials, No. 4, Chisinau, pp. 34-40.

- $\quad$ Luban, R. B.; Pecker, L. S.; Galinov, I. V. (1990). About a possible mechanism of material transfer from the anode to the cathode at electro-spark alloying of metals. Electronic processing of materials. No. 5, pp. 13-14.

- Topală, P. (2007). Electrical charges as measure for removed metal mass the electrical discharge machining. Iasi: Edition PIM, Nonconventional Technologies Review, No. 4, pp. 103108.

- $\quad$ Topală, P.; Stoicev, P., (2008). Conductive material processing technologies by applying electrical discharges in impulse. Chisinau: Edition „Tehnica-INFO”, 265 pp.

- $\quad$ Stavitskii, V. I. (2001). Precision electro-spark material processing. Scientific basis of precise shaping of material surfaces. Electronic processing of materials, No. 6, Chisinau, pp. 5-32.

- $\quad$ Topală, P., Dushenko, V., Gitlevich, A., (1990). On the conditions of surface melt formation on the piece-cathode during electro-spark alloying at "Razread" type installations. Electronic processing of materials, No. 6, Chisinau, pp. 17-18.

- Topală, P., Rusnac V., Guzgan, D. Increasing the thermoelectric capacity of emission in cathodes by modifying their surface microgeometry. The 16th International Conference Inventica 2012, June 13-15, 2012, Iasi, Romania. Edition Performantica, National Institute of Inventica, Iasi. pp. 623-624. ISSN 1844-7880.

- $\quad$ Topală, P., Guzgan, D. Formation of electronic thermo-emission surfaces via micro-geometry modification under conditions of applying EDI plasma. Proceedings of the 17th International Conference ModTech - New face of TMCR, 2013. Sinaia, Romania. ISSN 2066-3919. 